\title{
The Influence of Leadership Style on Strategic Decision in Response to Organizational Change
}

\author{
Nazirah Aziz¹, Tuan Zainun Tuan Mat ${ }^{1}$, Zairul Nurshazana Zainuddin ${ }^{1}$, Anrusha Bhana² \\ ${ }^{1}$ Faculty of Accountancy, Universiti Teknologi MARA, Puncak Alam, Malaysia. \\ ${ }^{2}$ Durban University of Technology, South Africa
}

nazirahaziz@uitm.edu.my, tuanz693@uitm.edu.my, zairul2384@uitm.edu.my,AnrushaB@dut.ac.za

Tel of 1st Author: (+60)332584978/ (+60)196025788

\begin{abstract}
With the impact of the Covid-19 pandemic, businesses have to take extensive change initiatives to stay competitive in the market. This paper addresses the significant role of the leaders in making strategic decisions to ensure business sustainability. This paper explores the influence of leadership styles on strategic decisions by reviewing past literature that discusses the relationship between various leadership styles and strategic decisions. The findings of this study will enhance the strategic decisions by identifying the prominent leadership style practiced by SMEs in facing change necessitated by the Covid-19 pandemic.
\end{abstract}

Keywords: Leadership styles; Strategic decision; Small Medium Enterprise; Organizational change.

eISSN: 2398-42870 2021. The Authors. Published for AMER ABRA cE-Bs by e-International Publishing House, Ltd., UK. This is an open access article under the CC BYNC-ND license (http://creativecommons.org/licenses/by-nc-nd/4.0/). Peer-review under responsibility of AMER (Association of Malaysian Environment-Behaviour Researchers), ABRA (Association of Behavioural Researchers on Asians/Africans/Arabians) and CE-Bs (Centre for Environment-Behaviour Studies), Faculty of Architecture, Planning \& Surveying, Universiti Teknologi MARA, Malaysia.

DOI: https://doi.org/10.21834/ebpj.v6i17.2849

\subsection{Introduction}

The importance of posing suitable leadership styles has grown significantly in organizations compared with the past due to several factors such as globalization, rapid technological changes, and the adoption of digitalization in the economy. The demanding factors have forced the top management to adapt to these unprecedented changes. With the impact of the Covid-19 pandemic, many have taken extensive change initiatives to continuously transform the organizations towards improving the performance and stay competitive in the market. Among other change initiatives taken is the adoption of digitalization to adapt to the current Covid-19 pandemic. To keep pace with these changes, firms need to analyze consumer-driven changes, adopt technological transformation, and operate in a highly competitive market.

The business environment is changing rapidly and becoming impulsive and volatile due to the Covid-19 pandemic. According to a report published by the SME Corporation Malaysia, the pandemic has affected almost 98.5 percent of Malaysian businesses, including SMEs and micro SMEs (SME Corporation Malaysia, 2020).

Organizations try to cope with such a 'new' environment and adopt strategic decisions to achieve successful change. Prior literature suggests that poor leadership could lead to failure to embrace change (Yasir et al., 2016). Ch'erif, García, Miquel, and Castillo (2021) examine the practice of ethical leadership during a crisis due to the Covid-19 pandemic.

eISSN: 2398-42870 2021. The Authors. Published for AMER ABRA cE-Bs by e-International Publishing House, Ltd., UK. This is an open access article under the CC BYNC-ND license (http://creativecommons.org/licenses/by-nc-nd/4.0/). Peer-review under responsibility of AMER (Association of Malaysian Environment-Behaviour Researchers), ABRA (Association of Behavioural Researchers on Asians/Africans/Arabians) and CE-Bs (Centre for Environment-Behaviour Studies), Faculty of Architecture, Planning \& Surveying, Universiti Teknologi MARA, Malaysia.

DOI: https://doi.org/10.21834/ebpj.v6i17.2849 
The author addressed the need to adapt leadership styles that suit the current situation in facing the external threats due to the Covid-19 pandemic. In addition, leaders are also accountable for playing an influential role in protecting their business and team while preserving the resources and pursuing development to improve their future wealth.

Successful and committed leaders must deal with the new and unpredictable environment to help the organization best change. Organizations aiming towards successful implementation of change need to focus on the leadership quality in making strategic decisions. Leaders will act as the change agents to support the employees to accept change. Failure to impose leadership quality among leaders could lead to a loss in change which could jeopardize business sustainability.

\subsection{Research background}

The current study views the impact of Covid-19 pandemic that can push the business to adopt change to maintain their survival in the market. Organizational change refers to the process of transitioning from one state to another, altering the internal process or adapting with the current technology. Many businesses are now facing loss of income as they cannot operate the business as usual due to the restrictions imposed by the authorities.

This study views the significant role of the Small Medium Enterprises (SMEs) leaders in managing change, particularly in shaping the future of their organization through their strategic decision. Good leaders should possess the right qualities, and they are also able to evaluate the needs of their followers and the situation at hand. This study asserts that leaders must play significant roles in directing their businesses towards successful change. This study explores the relationship of the leadership styles during an organizational change from prior research by reviewing the past literature. This study also focuses on how has the Covid-19 pandemic change the leadership styles of the top management. In addition, this study also explores to what extent the leadership style influences the strategic decision made by the top management in adapting successful implementation of organizational change necessitated by the Covid-19. The findings of this study will assist SME leaders in identifying and adapting the significant leadership styles to assist them in managing their organization during change. In addition, this study will also contribute towards enhancing the strategic business decision by identifying the prominent leadership style practiced by SMEs in facing change.

\subsection{Research objectives}

The broad objective of this study is to explore the relationship of leadership styles on the business strategic decisions played by SME leaders during organizational change necessitated by the Covid-19 pandemic. Specifically, the purpose of the current study are as follows:

RO 1: To explore the leadership styles played by the leaders during organizational change from prior research by reviewing the past literature.

RO 2: To identify the most prominent leadership styles played by the leaders towards improving strategic decisions.

RO 3: To propose the leadership styles that can enhance SME business' strategic decisions.

\subsection{Theories underpinned the study}

The Contingency Theory and Behavioral Theory were employed to explain the importance of posturing the right leadership style during organizational change. The Contingency Theory highlights different variables in a specific setting that determine the type of leadership style best suited for the said situation. Prior research noted the principle that no one leadership style applies to all cases. Renowned leadership scholars Hodgson and White believe that an excellent leader finds the perfect balance between behaviors, needs, and context. Good leaders should possess the right qualities and assess the needs of their followers and the organization's condition at hand. In summary, the contingency theory proposes that outstanding leadership is a combination of many factors that make individuals great leaders.

In Behavioral Theory, the focus is on leaders' specific behaviors and actions rather than their traits or characteristics. The theory highlights that effective leadership is the result of many learned skills. Individuals need to acquire the three primary skills to lead their followers, namely technical, human, and conceptual skills. Technical skills refer to a leader's knowledge of the process or technique; human skills mean that one can interact with other individuals, while conceptual skills enable the leader to develop ideas for running the organization or society smoothly.

\subsection{Literature Review}

\subsection{Strategic decisions}

Strategic decisions refer to the response made to achieve organizational goals. The decision made could take the companies in new direction that may or may fail. Strategic management scholars address the need for firms to pose strategic response-ability to achieve firm competitiveness in a changing environment.

According to Onamusi (2020), change can be characterized by technological transformation, unpredictable consumer behavior, intense global and local competition, government policies, disruptive innovations, and inflation. The present study views the Covid-19 pandemic as one of the factors that impulse the business to adapt to a changing environment. According to Pearce and Robinson (2005), a strategic response refers to a set of decisions and actions that produce a formal execution plan to achieve a firm's objectives. Hence, it is a reaction to the situation happening in the economic environment or organizations. Affandi and Affandi (2019) addressed that organizations produce two strategic responses to cope with the crisis: proactive and reactive. A proactive response is a reaction to 
issues in early stages that become crises at later stages, which involves anticipating problems and changes in how things are done. Proactive strategy is an approach to provide a solution to business competition and workplace changes based on anticipation. Meanwhile, a reactive response is shown in response to a situation that becomes a crisis for businesses. Reactive tactic provides a slow reaction to changes in the firm's environment, where issues are addressed after they take the trouble.

\subsection{Leadership styles}

Leadership refers to individual traits and behaviors and their relationships with the followers and stakeholders (Albooshi et al., 2020; Nusair et al., 2012). Leadership refers to communicating a vision and engaging followers and other stakeholders in achieving that vision (Gupta et al., 2004). Leadership also denotes the administrative position in an organization. Leadership has a role in creating, influencing, and supporting their followers to improve performance (Albooshi et al., 2020). Jong and Hartog (2007) addressed that leadership also affects people to get the desired result. The leaders can stimulate, motivate, and recognize their employees' potential to get work done (Andersen, 2016). According to Lok and Crawford (2004), leadership style may lead to a better prediction of the success or failure of an organization. Thus, top-quality leadership is essential to achieve the mission and vision and cope with the changes occurring in the external environment (Harris, et al., 2007). Leaders play a significant role during organizational change through their commitment to support the change initiatives. Chang (2016) viewed leaders as human change agents in facilitating the change process. Leaders should inspire and encourage the followers and make them aware of the current situation and reason for the change. Asrar-ulHaqa \& Kuchinkeb (2016), in their previous study, claimed that leaders adopt various leadership styles to motivate their employees.

\subsubsection{Transformational leadership}

Transformational leaders can inspire and transform their subordinates from being self-oriented to higher levels of enthusiasm (Albooshi et al., 2020). Transformational leaders also possess visionary leadership to motivate their employees to exceed performance expectations (Doucet et al., 2015). A transformational leader is a charismatic leader who inspires people through his vision. Burns (1978) introduced the concept of transformational leadership by influencing the beliefs and attitudes of the employees through inspiring them. According to Tajasom, Hung, Nikbin, and Hyun (2015), transformational leaders help their followers accomplish the organizational goals and mission by working together. Transformational leaders motivate their employees in emotional attachment, which goes beyond any rewards and returns. Martin (2016) also addressed that transformational leaders initiate organizational change and encourage their subordinates to understand the importance of change, which can ultimately lessen change resistance.

Prior research also found that transformational leadership practices influence the followers to achieve goals and increase confidence, commitment, and job performance (Bono \& Judge, 2003). Carnes, Houghton, and Ellison (2015) highlighted that one of the most crucial success factors for any organization is identifying and selecting influential leaders. Albooshi et al. (2020) also addressed that transformational leaders influence strategic decisions by influencing the behavior of the subordinates through a commitment to change and increase their willingness to accept and adopt change. Past research also addressed that transformational leadership styles tend to be a better fit during periods of change. Leaders can identify the change signals and the needs for change to ensure their survival in the competitive environment (Villaluz \& Hechanova, 2019; Vargas, 2015).

\subsubsection{Transactional leadership}

According to Uchenwamgbe (2013), a leader is a transactional leader if they are always willing to give something in return. Bass (1997) mentioned that a transactional leader uses a carrot and stick approach to achieve desired outcomes. Thus, it is considered a classical management approach to influence the followers though close monitoring and taking corrective actions where necessary. Employees will be rewarded if successful in accomplishing their goals. Transactional leaders are more concerned with the completion of tasks and employees' performance. They use both positive and negative reinforcements to achieve the desired results. Transactional leaders do not expect any innovative ways of doing the task from their employees (Hartog \& Van Muijen, 1997). According to Smith, Eldridge, and DeJoy (2016), transactional leadership is used as a corrective approach and has two dimensions: contingent reward and management by exception (active and passive). Contingent reward means firms will introduce bonuses and promotions to employees to gain their cooperation. For management by exception, leaders are more prone to corrective actions when things go wrong and out of control.

There are two types; management by exception active and management by exception passive. Management by exception dynamic suggests that the leader proposes the anticipation behavior. The leader with this transactional leadership style tries to solve the problem before they are likely to occur. For management by exception passive, the leader does not anticipate the future situation but acts when issues arise.

\subsubsection{Entrepreneurial leadership}

Leaders with entrepreneurial behaviors are passionate, confident, and willing to initiate change. Entrepreneurial leaders consider the surrounding environment and quickly identify the necessary action to maintain their survival (Ricard et al., 2017). Thus, entrepreneurial leaders will grab the opportunities to create more wealth and adapt to the environmental uncertainties that forced them to change. In addition to this, entrepreneurial leaders will also encourage their employee's motivation and courage to prepare for future volatility in the market.

\subsubsection{Strategic leadership}

Strategic leadership analyzes the business environment, then creates and communicates the strategic decisions with the team members towards achieving vision and mission. Strategic leaders develop strategic business decisions based on market trends and volatility in 
complex environments (Hou et al., 2019). Strategic leaders set a vision for their organization to adapt to technological changes and remain competitive in a changing economy.

\subsubsection{Laissez faire leadership}

Leaders with this style of leadership tend to avoid making decisions process. Laissez-faire leaders are usually reluctant to take action and avoid situations, resulting in encountering problems. Leaders with laissez-faire leadership styles do not provide any medium to get feedback from the employees. They do not even use rewards to satisfy the needs of their employees. Therefore, this could lead to dissatisfaction feeling, unproductive manner, and inefficiency in their work done.

\subsubsection{Other leadership styles in behavioural studies}

Albooshi et al. (2020) conducted a comprehensive review of prior research on the influence of leaderships on business innovation. In addition to the leadership styles mentioned above, the authors also addressed the following leadership styles in behavioral studies: ambidextrous leadership, charismatic leadership, ethical leadership, paternalistic leadership, humorous leadership, and spiritual leadership. Furthermore, Albooshi et al. (2020) also summarized the leadership styles played by the leaders towards improving business innovation such as developmental leadership, participative leadership, integrative leadership, self-leadership, and CEO leadership.

\subsubsection{Leadership styles and strategic decision}

The top managers are the most crucial assets of organizations, and their leadership styles significantly contribute to successful or unsuccessful business performance. Prior research addressed that leadership styles are the foremost environmental factor essential in influencing organizational performance and strategic decisions (Wu, JimWu, and Li, 2017). Therefore, this indicates that the personality traits of the leaders are the most prominent factors in directing the business towards successful performance through strategic decisionmaking (Yu Li, 2017). The leaders, including the business owner and managers, characterize the vision and mission and lead the subordinates towards fulfilling organizational objectives. One of the most critical factors that contribute to the successful strategic business decision are the leadership style of the managers (Çelik, Güngör \& Özkul, 2016). In this respect, leaders will provide direction, guide organizational priorities, and create a supportive environment to ensure successful adaptation with change initiatives (Alblooshi et al., 2020). Abuzaid et al. (2019) addressed that the transformational leadership style positively affects the Jordanian Microfinance companies' strategic decisions. Hence, organizations need to focus on developing the transformational leadership capabilities for their managers towards improving the strategic decisions.

The future survival and development depend on the leaders' strategic decisions (Wu et al., 2017). Thus, SMEs leaders must focus on enhancing a tacit understanding and support between team members regarding their perception, participation, risk assessment, and control towards improving strategic decision making. SMEs leaders should have personal traits in analyzing the current situation and making the right decisions to ensure the sustainability of the business. Decisions made by the managers during organizational change will shape the future of their organization.

Porfírio, Carrilho, Felício, and Jardim (2021) addressed digital transformation that forces businesses to adopt organizational change. The authors found that the democratic leadership styles, with a higher level of coherence towards the firm's mission and management efficacy in strategic decisions, are essential to explain the adoption of digital transformation during organizational change. In addition to this, leaders are also responsible for disseminating all relevant information about the needs for change with the subordinates to mobilize actions towards adopting digital transformation. The authors also stressed the managers' significant role in adapting to change driven by digital transformation. The involvement of the leaders in the digital transformation process is crucial as it will increase their knowledge and ability to influence the subordinates to accept change.

\subsection{Methodology}

This study aims to explore and review the literature on leadership styles and strategic decisions. This study views the organization's needs to adapt to the current situation where the pandemic Covid-19 started to affect the sustainability of the business. Most of the existing literature focuses on particular styles of leadership only. Therefore, the literature review approach in this study highlights the urgent need for a quantitative method for future research on the relationship between leadership and strategic decisions.

The search strategy for this study started with establishing a literature review component outline that guided the keywords used in the search database. Keywords included but not limited are strategic decisions, leadership styles, organizational change, Small Medium Enterprise. ScienceDirect database and Google Scholar were the main platforms used to search for information, including peer-reviewed journal articles, books, theses, and dissertation in related fields. Over 30 sources dating from 2000 to 2021 were identified. The majority of the sources cited in the present study were published within the last five years.

\subsection{Discussion}

Leaders are the key to making a successful strategic business decision, given their ability to influence their followers to accept new ideas and adapt to the market situation. Different leadership styles have a different impact on strategic decisions. Decisions made by the leaders will affect the future of their organization. SMEs leaders are encouraged to engage with the subordinates, especially during the organizational change, to enhance strategic decisions. The SMEs leaders, including the business owner and managers, must be 
participative, have excellent competency, and use informative approaches to address change needed to adapt to the current situation and achieve successful strategic decisions. SME leaders need to act strategically to adapt to technological changes and remain competitive in a changing economy.

As a strategic leader, the SME business owner and managers will integrate the vision and innovation necessary for their business's long-term success. Villaluz and Hechanova (2019) noted that leaders inspire followers and make them more aware of the importance of the organizational mission and goals to think creatively and perform beyond expectations. Leaders recognize their employees' contributions and continuously encourage them to look for new ideas internally and externally. Leaders also promote organizational learning, considered one of the most critical drivers of successful strategic decisions.

Colovic (2021) examined the leadership style and business model innovation during the organizational change process due to internationalization has pointed out that the SMEs model innovation led by the directive leadership style. Directive leadership involves leaders ordering followers to carry out the tasks to achieve firm's objectives. Thus, it is associated with an influential leader giving clear directions to followers, leaving little freedom for them to decide and act (Lorinkova et al., 2013)

Prior research suggested that the transformational leadership style positively affects the effectiveness of strategic decisions (Urbano, Felix, Aparicio, 2021; Abuzaid et al., 2019). Managers with transformational and transactional leadership styles were supportive and involved with their subordinates (Holten \& Brenner, 2013). Hence, this indicates that the managers' engagement with followers during the change process is necessary to accept change positively. Skakon et al. (2010) also addressed the managers are the drivers of change, and hence, they play essential roles in ensuring successful change initiatives. Abdul Halim Busari et al. (2019) also suggested that managers with transformational leadership behavior play an important role in shaping the employees' positive and reactions towards change. The authors also highlighted that transformational leadership is essential in shaping employee's responses, with active participation contributing to leadership in the change process. Thus, organizations need to focus on developing the transformational leadership capabilities for their managers towards improving the strategic decisions. Therefore, this also includes focusing more on developing the managers' transformational leadership capability by equipping them with adequate training programs in different aspects of transformational leadership.

\subsection{Conclusion and Recommendations}

This paper explores the past literature on the influence of leadership styles of SMEs leaders on strategic decisions during organizational change necessitated by the Covid-19 pandemic. Reports addresses that SMEs are the most prominent entity affected by the Covid-19 pandemic. SMEs tried to cope with the new business environment and started to adopt strategic decisions to ensure their survival in the market. Based on the review of past literature, this study found that the transformational and transactional leadership styles are the most prominent practiced by the leaders during organizational change. This study proposes that SME leaders consider other factors to enhance strategic decisions during organizational change, including improving managerial acceptance of change, generating new ideas, and providing innovative alternatives and choices to ensure a successful transition.

This study has several limitations to be acknowledged to provide opportunities for further studies. The present study only addressed the review of past literature on leadership styles strategic decisions during organizational change as characterized by technological change, financial crisis, innovation, and competition in the market. Future studies may adopt a cross-sectional survey design to investigate the relationship between leadership styles and strategic decisions. Future studies may also be conducted in two different settings involving developed and developing countries to examine the influence of leadership styles on strategic decisions.

\section{Acknowledgements}

We gratefully acknowledge the financial support from the Faculty of Accountancy, Universiti Teknologi MARA, Puncak Alam Campus, for funding through an internal research grant.

\section{Paper Contribution to Related Field of Study}

This paper contributes to the field of Strategic management accounting and behavioral research, specifically in the field of leadership styles, strategic decisions, organizational change, and research on Small Medium Enterprise.

\section{References}

Abuzaid, A. N., Al-Ma'iaitah, N., Al-Haraisa, Y. E., and Al-Tarawneh, K. I. (2019). Examining the Impact of Transformational Leadership on the Strategic Decision Effectiveness of Jordanian Microfinance Companies. International Review of Management and Marketing, 9 (2), 76-83.

Affandi, S. and Affandi, H. (2019). Impact of crisis management practices and strategic response on pricing strategy: evidence from textile industry in Pakistan, Review of Economics and Development Studies Vol. 5, No 4.

Alblooshi, M., Shamsuzzaman, M. \& Haridy, S. (2020). The relationship between leadership styles and organisational innovation: A systematic literature review and narrative, synthesis. European Journal of Innovation Management, 1460-1060 DOI 10.1108/EJIM-11-2019-0339

Bono, J.E. \& Judge, T.A., (2003). Self-concordance at work: toward understanding the motivational effects of transformational leaders. Academy of Management Journal, $3,554-71$. 
Busari, A. H., Khan, S. N., Abdullah S. M., and Mughal, Y. H. (2020). Transformational leadership style, followership, and factors of employees' reactions towards organizational change, Journal of Asia business studies, 14 (2), 181-209.

Çelik, S. Güngör, A. \& Özkul, E. (2016). The Relationship Between Strategic Decision-Making and Leadership Styles: An Application in 4 and 5-Star Hotels in Istanbul. Journal of Business Research Turk. 240-264

Chang, Y. (2016). Multilevel transformational leadership and management innovation:intermediate linkage evidence. Leadership and Organization Development Journal, 37 (2), 265-288.

Ch'erif, O. A., García, M. G., Miquel, J. C. B., Castillo, A. C. (2021). Being an ethical leader during the apocalypse: Lessons from the walking dead to face the COVID-19 crisis. Journal of Business Research, 133, 354-364.

Chen, L., Zheng, W., Yang, B. and Bai, S. (2016). Transformational leadership, leader support, and employee creativity. Leadership and Organization Development Journal, 37 (7), 843-859.

Colovic, A. (2021), Leadership and business model innovation in late internationalizing SMEs, Long Range Planning, https://doi.org/10.1016/j.Irp.2021.102083

Gupta, V., MacMillan, I.C., Surie, G., (2004). Entrepreneurial leadership: developing and measuring a cross-cultural construct. Journal of Business Venture 19 (2), 241260.

Harris, A. et al.,(2007). Distributed leadership and organizational change: Reviewing the evidence. Journal of Educational Change, 8(4), 337-347.

Hou, B., Hong, J., Zhu, K. and Zhou, Y. (2019). Paternalistic leadership and innovation: the moderating effect of environmental dynamism. European Journal of Innovation Management, 22 (3), 562-582.

Martin, J. (2016). Perceptions of transformational leadership in academic libraries. Journal of Library Administration, 56 (3), $266-284$.

Nusair, N., Ababneh, R. and Bae, Y.K. (2012). The impact of transformational leadership style on innovation as perceived by public employees in Jordan. International Journal of Commerce and Management, 22 (3), 182-201.

Onamusi, A. B. (2020). Strategic response capability and firm competitiveness: how omoluabi leadership makes a difference. Business Excellence and Management, Vol $10(4)$

Pearce, J.A and Robinson, R. (2005). Strategic Management: Strategic Formulation and Implementation. 3rd Edition. Richard D. Irwin Inc. U.S.A.

Porfírio, J. A., Carrilho, T., Felício, J. A, and Jardim, J. (2021). Leadership characteristics and digital transformation. Journal of Business Research. 124, 610-619.

Ricard, L.M., Klijn, E.H., Lew, J.M. and Ysa, T. (2017). Assessing public leadership styles for innovation: a comparison of Copenhagen, Rotterdam and Barcelona", Public Management Review, 19 (2), 134-156.

SME Corporation Malaysia (2020)

Urbano, D., Felix, C., Aparicio, S. (2021). Informal institutions and leadership behavior in a developing country: A comparison between rural and urban areas. Journal of Business Research, 132, 544-556.

Uchenwamgbe, B.-B. P., (2013). Effects of Leadership Style on Organizational Performance in Small and Medium Scale Enterprises (SMEs) in Nigeria. European Journal of Business and Management, 5(23),53-73.

Vargas, M.I.R. (2015). Determinant factors for small business to achieve innovation, high performance and competitiveness: organizational learning and leadership style", in Procedia -Social and Behavioral Sciences proceedings of the 6th Indonesia International Conference on Innovation, Entrepreneurship and Small Business, 169, 4352.

Villaluz, V.C. and Hechanova, M.R.M. (2019). Ownership and leadership in building an innovation culture. Leadership and Organization Development Journal, 40 (2), $138-150$

Wu, T., JimWu, Y., Tsai, H., and Li, Y.(2017). Top management teams' characteristics and strategic decision-making: a mediation of risk perceptions and mental models Sustainability, 9, 2265; doi:10.3390/su9122265

Yasir, Muhammad, Imran, Rabia, Irshad, Muhammad Kashif, Mohamad, Noor Azmi, \& Khan, Muhammad Muddasssar. (2016). Leadership styles in relation to employees' trust and organizational change capacity: evidence from non-profit organizations. SAGE Open, 6(4).

Yu Li, P. (2017). The impact of the top management teams' knowledge and experience on strategic decisions and performance. Journal of Management \& Organization, 23 (4), pp. 504-523 